\title{
Interactions of Bordetella pertussis adenylyl cyclase toxin CyaA with calmodulin mutants and calmodulin antagonists: Comparison with membranous adenylyl cyclase I
}

\author{
Dominik Schuler ${ }^{\# a}$, Carolin Lübker ${ }^{\# a}$, Gerald H. Lushington ${ }^{b}$, Wei-Jen Tang ${ }^{c}$, Yuequan \\ Shen ${ }^{d}$, Mark Richter ${ }^{\mathrm{e}}$, and Roland Seifert ${ }^{\mathrm{a},{ }^{*}}$ \\ a Institute of Pharmacology, Hannover Medical School, Carl-Neuberg-Str. 1, D-30625 Hannover, \\ Germany \\ b Molecular Graphics and Modeling Laboratory, The University of Kansas, KS 66045, USA \\ c Ben May Department of Cancer Research, The University of Chicago, Chicago, IL 60637, USA \\ d College of Life Sciences, Nankai University, 300071 Tianjin, People's Republic of China \\ e Department of Molecular Biosciences, The University of Kansas, Lawrence, KS 66045, USA \\ \# These authors contributed equally to this work.
}

\section{Abstract}

The adenylyl cyclase (AC) toxin CyaA from Bordetella pertussis constitutes an important virulence factor for the pathogenesis of whooping cough. CyaA is activated by calmodulin (CaM) and compromises host defense by excessive cAMP production. Hence, pharmacological modulation of the $\mathrm{CyaA} / \mathrm{CaM}$ interaction could constitute a promising approach to treat whooping cough, provided that interactions of endogenous effector proteins with CaM are not affected. As a first step toward this ambitious goal we examined the interactions of CyaA with wild-type CaM and four $\mathrm{CaM}$ mutants in which most methionine residues were replaced by leucine residues and studied the effects of the CaM antagonists calmidazolium, trifluoperazine and $\mathrm{N}$-(6aminohexyl)-5-chloro-1-naphthalenesulfonamide (W-7). CyaA/CaM interaction was monitored by CaM-dependent fluorescence resonance energy transfer (FRET) between tryptophan residues in CyaA and 2'-(N-methylanthraniloyl)-3'-deoxy-adenosine $5^{\prime}$-triphosphate and catalytic activity. Comparison of the concentration/response curves of $\mathrm{CaM}$ and $\mathrm{CaM}$ mutants for FRET and catalysis revealed differences, suggesting a two-step activation mechanism of CyaA by CaM. Even in the absence of $\mathrm{CaM}$, calmidazolium inhibited catalysis, and it did so according to a biphasic function. Trifluoperazine and W-7 did not inhibit FRET or catalysis. In contrast to CyaA, some $\mathrm{CaM}$ mutants were more efficacious than $\mathrm{CaM}$ at activating membranous $\mathrm{AC}$ isoform 1 . The slope of CyaA activation by $\mathrm{CaM}$ was much steeper than of $\mathrm{AC} 1$ activation. Collectively, the twostep activation mechanism of CyaA by $\mathrm{CaM}$ offers opportunities for pharmacological intervention. The failure of classic $\mathrm{CaM}$ inhibitors to interfere with $\mathrm{CyaA} / \mathrm{CaM}$ interactions and the different interactions of $\mathrm{CaM}$ mutants with $\mathrm{CyaA}$ and $\mathrm{AC} 1$ point to unique $\mathrm{CyaA} / \mathrm{CaM}$ interactions.

(c) 2012 Elsevier Inc. All rights reserved.

"Corresponding author. Tel.: +49 511532 2805; fax: +49 511532 4081. seifert.roland@ @mh-hannover.de (R. Seifert).. Appendix A. Supplementary data

Supplementary data associated with this article can be found, in the online version, at doi:10.1016/j.bcp.2012.01.005. 


\section{Keywords}

Bordetella pertussis; Adenylyl cyclase; Calmodulin; Fluorescence spectroscopy; Calmodulin antagonists

\section{Introduction}

CyaA is a $188 \mathrm{kDa}$ exotoxin secreted from Bordetella pertussis with a $\mathrm{N}$-terminal AC domain of a $\sim 400$ amino acids and a C-terminal hemolysin domain of $\sim 1300$ amino acids which is also responsible for toxin insertion into host cells [1-4]. CyaA is an important virulence factor for the pathogenesis of whooping cough. Following insertion into the plasma membrane of host cells, CyaA binds $\mathrm{CaM}$ with high affinity. CaM induces a conformational change in CyaA, resulting in very high cAMP formation rates [1-4]. As a result, the function of immune cells is compromised, and the infection with Bordetella pertussis becomes more severe and prolonged.

Recently, despite wide-spread vaccination programs, increasing numbers of whooping cough outbreaks have been noted in geographical regions ranging from Ireland to New Zealand and in diverse sociocultural settings including military schools and university laboratories [5-10]. These findings show that whooping cough is still an important medical problem and accordingly, novel therapeutic approaches are required. One strategy to treat whooping cough is to block the function of CyaA by inhibitors. Three sites of intervention can be envisaged. First, one could target the catalytic site $[4,11,12]$. Indeed, recently, we have developed a novel class of Bis-MANT-nucleotides that inhibit CyaA with high selectivity relative to mammalian ACs [13]. Second, one could target CyaA/CaM interaction [14], and third, one could target other allosteric sites in CyaA that are important for the conformational changes during activation [15]. When targeting CyaA/CaM interaction, one should keep in mind that $\mathrm{CaM}$ regulates numerous mammalian cell effector proteins including myosin light-chain kinase, sarcoplasmic $\mathrm{Ca}^{2+}$ ATPase, phosphodiesterases, nitric oxide synthases and mammalian AC isoforms 1 and 8 [16-24].

The specific aims of our present study were first to better understand the $\mathrm{CyaA} / \mathrm{CaM}$ interaction and second to examine the effects of $\mathrm{CaM}$ inhibitors on $\mathrm{CyaA} / \mathrm{CaM}$ interactions. To achieve the first aim, we compared the interactions of wild-type CaM with several CaM mutants in which most of the methionine residues were replaced by leucine residues (Table 1). The methionine-leucine exchange results only in minimal conformational changes in CaM [25]. To achieve the second aim, we examined the effects of calmidazolium, W-7 and trifluoperazine, three classic CaM inhibitors (Fig. 1) [16-18,26]. As first methodological approach, we studied conformational changes in CyaA by monitoring the fluorescence of $2^{\prime}$ MANT-3'-d-ATP. Upon binding of CaM to CyaA, the fluorescence of 2'-MANT-3'-d-ATP increases substantially as a result of an interaction of the MANT group with phenylalanine 306 [12]. Moreover, there is a strong CaM-dependent FRET from tyrosine and tryptophan residues of CyaA to the MANT group [12]. As second methodological approach, we examined the catalytic activity of CyaA in a radiometric assay [12]. In order to paradigmatically assess the specificity of the interaction of CyaA with CaM, we also examined the effects of $\mathrm{CaM}$ and $\mathrm{CaM}$ mutants on the catalytic activity of recombinant AC1. 


\section{Materials and methods}

\subsection{Materials}

Lyophilized CaM-WT from bovine brain (purity > 99\%), calmidazolium chloride and W-7 were from Merck (Darmstadt, Germany). The N-terminal catalytic domain of CyaA (CyaA$\mathrm{N})$, containing the amino acids 1-373 was expressed in E. coli with plasmid pEx-CyaA-N. CyaA-N was then purified as described [17]. Expression and purification of the four CaM mutants (CaM-206, -213, -214 and -215) were performed as described [25]. 2'-MANT-3'-dATP was obtained from Jena Bioscience (Jena, Germany). [a- $\left.{ }^{32} \mathrm{P}\right]$ ATP $(3000 \mathrm{Ci} / \mathrm{mmol})$ was purchased from Hartmann (Braunschweig, Germany). 3-Isobutyl-1-methylxanthine was from Sigma-Aldrich (Taufkirchen, Germany). Sources of all other materials were as described before $[12,13,27,28]$. AC1 was expressed in Sf9 insect cell membranes as described $[27,28]$.

\subsection{Direct fluorescence and fluorescence resonance energy transfer (FRET) experiments}

All fluorescence measurements were recorded on a Varian Cary Eclipse fluorescence spectrometer (Varian, Inc., Palo Alto, CA, USA) essentially as described [12]. Briefly, experiments were performed at $25^{\circ} \mathrm{C}$. Reaction buffer consisted of $100 \mathrm{mM} \mathrm{KCl}, 100 \mu \mathrm{M}$ $\mathrm{CaCl}_{2}, 5 \mathrm{mM} \mathrm{MnCl}_{2}$ and $75 \mathrm{mM}$ HEPES/NaOH, $\mathrm{pH}$ 7.4. Steady-state measurements were recorded in the scan mode from $\lambda_{\mathrm{em}}=300$ to $500 \mathrm{~nm}$ with $\lambda_{\mathrm{ex}}=280 \mathrm{~nm}$ and from $\lambda_{\mathrm{em}}=380$ to $540 \mathrm{~nm}$ with $\lambda_{\mathrm{ex}}=350 \mathrm{~nm}$. In the case of CaM-mutants experiments the cuvette contained first $49 \mathrm{ml}$ of reaction buffer. 2'-MANT-3'-d-ATP, CyaA-N and CaM were added stepwise each in a volume of $7 \mu \mathrm{l}$ (final concentration were $300 \mathrm{nM}$ each). The cuvette content was mixed after each addition, and final volume was $70 \mu \mathrm{l}$.

Steady-state measurements with CaM inhibitors were recorded as described for the CaM mutants. First, the cuvette contained 2'-MANT-3'-d-ATP (final concentration $300 \mathrm{nM}$ ), CyaA-N (final concentration $300 \mathrm{nM}$ ) and CaM (final concentration $100 \mathrm{nM}$ ). The CaM concentration was chosen as low as possible, to ensure that all $\mathrm{CaM}$ binding sites were occupied with inhibitor. Finally, the CaM inhibitors (calmidazolium, trifluoperazine and $\mathrm{W}-7$ ) were added at final concentrations ranging from $100 \mathrm{nM}$ to $10 \mu \mathrm{M}$. Measurements were first carried out in the kinetic mode to ensure steady-state conditions. In these experiments the fluorescence emission spectra were corrected by subtracting baseline fluorescence (buffer alone) and the baseline-corrected CaM inhibitor-dependent emission of each concentration of the inhibitor (buffer + inhibitor). The final DMSO concentration was kept constant at $1 \%(\mathrm{v} / \mathrm{v})$.

Time-dependent experiments were conducted in the kinetic modus. For the determination of the $\mathrm{EC}_{50}$ and $E_{\max }$ values the cuvette initially contained a volume of $70 \mu \mathrm{l}$ with following content: $56 \mu \mathrm{l}$ reaction buffer, $7 \mu \mathrm{l} 2^{\prime}$-MANT-3'-d-ATP (final concentration $300 \mathrm{nM}$ ) and 7 $\mu$ l CyaA-N (final concentration $300 \mathrm{nM}$ ). After 3 min one $\mu$ l of either CaM-WT or one of the mutants CaM-206, CaM-213, CaM-214 or CaM-215 (final concentration $10 \mathrm{nM}$ ) were added. Then, consecutively another $1 \mu \mathrm{l}$ of the different CaM concentrations were added to the cuvette. In each case seven CaM concentration steps $(10 \mathrm{nM}, 20 \mathrm{nM}, 45 \mathrm{nM}, 70 \mathrm{nM}, 120$ $\mathrm{nM}, 220 \mathrm{nM}$ and $320 \mathrm{nM}$ ) were analyzed. Equilibration time was always $3 \mathrm{~min}$. For CaMWT, it would have been desirable to use longer equilibration times than 3 min because equilibration was slower than with CaM mutants. However, since prolonged UV irradiation of samples beyond $24 \mathrm{~min}$ resulted in progressive decline of fluorescence, reflecting denaturation of $\mathrm{CyaA}$ and $\mathrm{CaM}$, we needed to find a technically feasible compromise.

To explore the binding of $\mathrm{CaM}$ to CyaA-N over the time, experiments were carried out by sequential addition of reaction buffer, $300 \mathrm{nM} 2^{\prime}$-MANT-3'-dATP, $300 \mathrm{nM}$ CyaA-N and 
final $300 \mathrm{nM}$ CaM-WT, CaM-206, CaM-213, CaM-214 or CaM-215. Binding kinetics were analyzed by the one-phase exponential association equation in GraphPad prism 5.04 software. Baseline fluorescence (reaction buffer + 2'-MANT-3'-dATP + CyaA-N) and initial time before the addition of $\mathrm{CaM}$ was subtracted.

In competition experiments the binding of $\mathrm{CaM}$ to CyaA-N was disrupted by successive addition of increasing calmidazolium concentrations $(1-10 \mu \mathrm{M})$. In this case the system was additionally excited at $\lambda_{\mathrm{ex}}=350 \mathrm{~nm}$ in order to analyze the changes in the direct fluorescence emission of $2^{\prime}$-MANT-3'-d-ATP at $\lambda_{\mathrm{em}}=350 \mathrm{~nm}$.

\subsection{AC activity assay}

AC activity was determined essentially as described [12]. Briefly, assay tubes contained 10 $\mu l$ of CaM-WT, CaM-206, CaM-213, CaM-214 or CaM-215 at final concentrations ranging from $10 \mathrm{pM}$ to $1 \mu \mathrm{M}$ to obtain saturated curves. Tubes were preincubated for $2 \mathrm{~min}$ at $25^{\circ} \mathrm{C}$ after the addition of $20 \mu \mathrm{l}$ reaction mixture. This reaction mixture consisted of (final) 100 $\mathrm{mM} \mathrm{KCl}, 5 \mathrm{mM}$ free $\mathrm{Mn}^{2+}, 10 \mu \mathrm{M}$ free $\mathrm{Ca}^{2+}, 100 \mu \mathrm{M}$ EGTA, $100 \mu \mathrm{M}$ cAMP, $40 \mu \mathrm{M}$ ATP and $\left[\mathrm{a}^{32} \mathrm{P}\right] \mathrm{ATP}(0.2 \mu \mathrm{Ci} / \mathrm{tube})$. Free concentrations of divalent cations were calculated with WebMax C standard (http:// www.stanford.edu/cpatton/webmaxcE.htm). The preincubation was carried out to ensure the formation of a steady-state equilibrium of complexing agents and divalent cations. Reactions were started by the addition of $20 \mu \mathrm{l}$ of CyaA-N. Final toxin concentration was $10 \mathrm{pM}$ CyaA-N. Tubes were incubated for $15 \mathrm{~min}$ at $25^{\circ} \mathrm{C}$.

For the analysis of the CaM inhibitor potency, the CaM concentration was chosen as low as possible, to ensure that all CaM binding sites were occupied with inhibitor but guarantee that the catalytic activity was not to low. CaM concentration was kept at $1 \mathrm{nM}$, whereas the concentrations of calmidazolium, trifluoperazine and W-7 ranged from $1 \mathrm{nM}$ to $10 \mu \mathrm{M}$. After the addition of $20 \mu \mathrm{l}$ of CyaA-N (final concentration $10 \mathrm{pM}$ ) the tubes were preincubated for $2 \mathrm{~min}$ at $25^{\circ} \mathrm{C}$. Reactions were initiated by the addition of $20 \mu \mathrm{l}$ reaction mixture. Reaction time was $15 \mathrm{~min}$ at $25^{\circ} \mathrm{C}$. The lipophilic compounds calmidazolium and W-7 were dissolved in dimethyl sulfoxide (DMSO) and in all experiments with inhibitors the final DMSO concentration was kept constant at $1 \%(\mathrm{v} / \mathrm{v})$.

For the evaluation of direct effects of the CaM inhibitors on CyaA-N, experiments were performed in the absence of $\mathrm{CaM}$ and $\mathrm{Ca}^{2+}$, respectively. Without the activation of $\mathrm{CaM}$ the catalytic activity of CyaA-N is about 10,000 times lower [29]. Therefore, the final toxin concentration was increased to $100 \mathrm{pM}$ and thus, the $\left[\mathrm{a}^{32} \mathrm{P}\right] \mathrm{ATP}$ concentration was increased as well $\left(0.8 \mu \mathrm{Ci} /\right.$ tube). In these experiments, reaction time was $30 \mathrm{~min}$ at $37{ }^{\circ} \mathrm{C}$. Concentrations of calmidazolium, trifluoperazine and W-7 ranged from $1 \mathrm{nM}$ to $100 \mu \mathrm{M}$.

The effect of $\mathrm{CaM}$ and $\mathrm{CaM}$ mutants on the activity of $\mathrm{AC} 1$ in $\mathrm{Sf} 9$ insect cell membranes was determined essentially as described [27,28]. Briefly, Sf9 membranes expressing AC1 $(20 \mu \mathrm{g} / \mathrm{tube})$ were pre-incubated for $2 \mathrm{~min}$ in the absence and the presence of CaM-WT or CaM mutants $(10 \mathrm{nM}-10 \mu \mathrm{M})$ at $30^{\circ} \mathrm{C}$. Reactions were initiated by the addition of reaction mixture containing $100 \mu \mathrm{M}$ 3-isobutyl-1-methylxanthine, $400 \mu \mathrm{M}$ EDTA, $5 \mathrm{mM} \mathrm{MgCl} 2,10$ $\mu \mathrm{M}$ free $\mathrm{Ca}^{2+}, 40 \mu \mathrm{M}$ ATP, $0.25 \mu \mathrm{Ci}$ [a- $\left.{ }^{32} \mathrm{P}\right] \mathrm{ATP}, 100 \mu \mathrm{M}$ cAMP, $0.4 \mathrm{mg} / \mathrm{ml}$ creatine kinase and $9 \mathrm{mM}$ phosphocreatine. Reactions were conducted for $20 \mathrm{~min}$ at $30^{\circ} \mathrm{C}$.

\subsection{Molecular modeling}

Relationships between the positions of mutated CaM methio-nine residues and the CaM/ CyaA interaction were probed in silico by analyzing the structure of the Bordetella pertussis AC toxin (PDB: 1YRT) [30] via the SYBYL software (version 8.1, Tripos, Inc., St. Louis MO, USA, 2009) to which protons had been added according to physiological pH (i.e., 
cationic arginine and lysine residues; anionic aspartates and glutamates). Using SYBYL's distance computation tool, each relevant $\mathrm{CaM}$ methionine was analyzed according to whether or not it coupled closely with CyaA (i.e., if it had any atoms within $4.0 \AA$ of any CyaA atom). Secondary structure assignments specified within the crystal structure were used to identify whether any CaM methionine was located within a CaM secondary structure element (i.e., was further than one residue away from the start or end of a specific a helix, $\beta$ strand or turn).

\subsection{Statistical analysis}

Time courses of CyaA activation by $\mathrm{CaM}$ and $\mathrm{CaM}$ mutants, concentration-response curves for the stimulatory effects of CaM and CaM mutants on FRET and catalytic activity of CyaA and AC1 were analyzed by non-linear regression using the software Prism 5.04 (GraphPad Prism, San Diego, CA, USA). The effects of CaM mutants versus CaM at CyaA were compared using one-way analysis of variance with a Dunnett's multiple comparison post test. In case of the analysis of $\mathrm{AC} 1$, the effects of $\mathrm{CaM}$ and $\mathrm{CaM}$ mutants were compared with each other using one-way analysis of variance with Bonferroni multiple comparison post test.

\section{Results}

\subsection{Analysis of the interaction of CyaA with CaM-WT and CaM mutants in steady-state FRET and direct fluorescence experiments}

At an excitation wavelength of $280 \mathrm{~nm}, 2^{\prime}$-MANT-3'-d-ATP showed only minimal fluorescence (Fig. S1). In contrast, CyaA, bearing numerous tyrosine and tryptophan residues $[12,13,30]$, showed substantial fluorescence with an emission maximum of $350 \mathrm{~nm}$. Upon addition to CyaA, both $\mathrm{CaM}-\mathrm{WT}$ and $\mathrm{CaM}$ mutants caused a significant FRET from tyrosine and tryptophan residues to the MANT group of $2^{\prime}$-MANT-3'-d-ATP as reflected by new emission peaks with a maximum at $430 \mathrm{~nm}$. The FRET signals were of very similar magnitude for all CaM proteins. However, we noted that for the CaM mutants, but not for CaM-WT, the endogenous tyrosine and tryptophan fluorescence of CyaA was increased, indicating that $\mathrm{CaM}-\mathrm{WT}$ and $\mathrm{CaM}$ mutants stabilize different CyaA conformations.

At a wavelength of $350 \mathrm{~nm}$, the MANT group of $2^{\prime}$-MANT-3'-d-ATP is excited and gives rise to a substantial fluorescence signal with an emission peak at $450 \mathrm{~nm}$ (Fig. S2). The addition of CyaA did not increase the fluorescence signal, but upon addition of CaM-WT or $\mathrm{CaM}$ mutants, a substantial fluorescence increase was noted, in addition to a blue-shift of the emission maximum to $430 \mathrm{~nm}$, reflecting effective interaction of the MANT group with phenylalanine 306 [12]. Again, no large differences between CaM-WT and CaM mutants were apparent.

\subsection{Kinetic analysis of the interaction of CyaA with CaM and CaM mutants in FRET experiments}

Fig. S3 shows representative time courses for the stimulatory effects of CaM-WT and CaM mutants on FRET, Fig. 2 shows merged time courses, and Table 2 summarizes the results of the non-linear regression analysis of kinetics. While CaM-WT and CaM mutants reached a similar maximum FRET, association proceeded in the order CaM-215 > CaM-214 > $\mathrm{CaM}-206>\mathrm{CaM}-213>\mathrm{CaM}$.

\subsection{Concentration/response curves for the interactions of CyaA with CaM-WT and CaM mutants in FRET experiments}

Fig. S4 shows representative cumulative concentration/response curves for the stimulatory effects of CaM-WT and CaM mutants on FRET, Fig. 3 shows the results of merged 
concentration/response curves and Table 3 summarizes the results of the nonlinear regression analysis of the curves. CaM-WT and CaM mutants increased FRET according to sigmoidal concentration/response curves with very similar maximum effects and $\mathrm{EC}_{50}$ values. No statistically significant differences between CaM-WT and CaM mutants were apparent.

\subsection{Concentration/response curves for the interactions of CyaA with CaM-WT and CaM mutants in AC assays}

Fig. 4 shows the results of merged concentration/response curves for the stimulatory effects of CaM-WT and CaM mutants on AC activity, and Table 4 summarizes the results of the non-linear regression analysis of the curves. CaM-WT and CaM mutants increased catalysis according to sigmoidal concentration/response curves. All CaM mutants were significantly less potent than CaMWT at activating catalysis. Moreover, CaM-214 and CaM-215 were significantly less efficacious than the other CaM proteins at stimulating cAMP formation.

\subsection{Effects of CaM antagonists on FRET, direct fluorescence and AC activity of CyaA in the presence and the absence of CaM}

Calmidazolium, trifluoperazine and W-7 are classic CaM antagonists [16-18,26]. However, trifluoperazine and W-7 failed to inhibit CaM-stimulated FRET (Fig. S5). Calmidazolium up to $1 \mu \mathrm{M}$ also failed to reduce FRET, and only at the exceedingly high concentration of 10 $\mu \mathrm{M}$, about four orders of magnitudes higher than the affinity for CaM [26], did calmidazolium partially reduce FRET. The three CaM antagonists revealed only partial inhibitory effects on direct fluorescence (Fig. S5).

Trifluoperazine and W-7 failed to inhibit CaM-stimulated catalysis of CyaA, and calmidazolium inhibited cAMP formation with an $\mathrm{IC}_{50}$ of $0.66 \mu \mathrm{M}$ (Fig. $5 \mathrm{~A}$ ). In the absence of CaM, the catalytic activity of CyaA is very low [29], but when the experimental conditions are adjusted accordingly, nonetheless, catalytic activity can be readily measured (see Section 2). In the absence of CaM, trifluoperazine and W-7 up to $10 \mu \mathrm{M}$ had no effect on catalysis. Only at the highest concentration $(100 \mu \mathrm{M})$ did the two inhibitors a slight inhibitory effect. In contrast, calmidazolium inhibited the catalytic activity of CyaA in the absence of CaM according to a biphasic function with a high-affinity $\mathrm{IC}_{50}$ of $340 \mathrm{nM}$ and a low-affinity $\mathrm{IC}_{50}$ of $34 \mu \mathrm{M}$.

\subsection{Concentration/response curves for the interactions of AC1 with CaM-WT and CaM mutants in AC assays}

Fig. S6 shows the absolute activities of AC1 with increasing concentrations of CaM-WT and $\mathrm{CaM}$ mutants. For all $\mathrm{CaM}$ proteins, shallow concentration/response curves with Hill slopes $<1.0$ were obtained (CaM-WT, 0.34; CaM-206, 0.61; CaM-213, 0.51; CaM-214, 0.32; CaM-215, 0.43). For none of the CaM proteins, saturation was reached at a concentration of up to $10 \mu \mathrm{M}$. Fig. $6 \mathrm{~A}$ shows that there were no significant differences in potency between CaM-WT and CaM mutants. However, we noticed differences in the magnitude of the stimulatory effects of $\mathrm{CaM}$ and $\mathrm{CaM}$ mutants at a concentration of $10 \mu \mathrm{M}$ each (Fig. 6B and C). Specifically, CaM-214 and CaM-215 were significantly more efficacious AC1 activators than CaM-WT.

\subsection{Molecular modeling of the interactions of CyaA with CaM}

Based on the crystal structure [30] it is possible to rationalize the observed effects that specific $\mathrm{CaM}$ mutations may have on the stability of the CyaA/CaM complex. Mutations to residues that directly impinge on the PPI interface and alter its steric or electrostatic character are among those likely to affect stability of the PPI complex. Mutations within 
secondary structure elements that significantly alter the steric or electrostatic profile may also affect the PPI stability by disrupting the stability of those secondary structure elements. Finally, mutations that are likely to affect intramolecular stabilization interactions (e.g., salt bridges and disulfide bonds) are also potentially important in that they may indirectly influence the stability of the PPI complex by favoring a different conformations within one of more of the participating proteins.

From Fig. 7, one sees that the four $\mathrm{CaM}$ methionine residues under investigation in this work are all situated at the periphery of the PPI interface, and thus their mutation may be expected to have some effect on stability of the complex. However; the methionine to leucine mutation (i.e., exchanging residues of similar size, shape and electrostatic profile) does not produce a substantially different protein surfaces that would significantly compromise PPI affinity. Furthermore, methionine and leucine have similarly favorable helix-forming propensities ( 0.24 and 0.21 , respectively) [31], so the fact that all four mutated methionine residues occur in a-helices also does not suggest likely destabilization of the PPI via secondary-structure disruption. Finally, methionines and leucines do not participate in salt bridges or disulfide bonds, and have similar propensity for engaging in weaker lipophilic stabilization mechanisms, thus once again arguing for at most a modest impact on the PPI stability.

\section{Discussion}

\subsection{Interactions of CyaA with CaM mutants: evidence for a two-step mechanism of activation}

$\mathrm{CaM}$ is an important $\mathrm{Ca}^{2+}$ sensor in mammalian cells and regulates the activity of numerous effector proteins including various kinases, $\mathrm{Ca}^{2+}$ ATPase, ion channels and AC1 [32,33]. The amino acid sequences recognized by $\mathrm{CaM}$ are quite diverse [34], and several mechanisms by which CaM activates is targets, have been described [35]. The mechanism of CaM-CyaA interaction is unique. Strikingly, CyaA and another bacterial AC toxin, edema factor from Bacillus anthracis, interact in distinct manners with CaM [30,36]. CaM interacts with four different regions in CyaA to stabilize a catalytically active conformation [30]. Hydrophobic interactions of methionine residues 109, 124, 144 and 145 in CaM with CyaA are of particular importance for PPI as revealed by crystallographic studies (Fig. 7) [30]. This notion is supported by the fact that oxidation of methionine residues 109, 124 and 145 reduces the affinity of CyaA for CaM mutants [37].

The long-term goal of our group is the development of specific inhibitors of the catalytic activity of CyaA since CyaA contributes substantially to the pathogenesis of whooping cough, a major health problem [5-10]. One possible strategy is to target the CyaA/CaM interaction [14,37]. Accordingly, it is very important to understand in detail this PPI. Originally, already in this study, we intended to take advantage of the methionine oxidation approach, assuming that the exchange of methionine against leucine residues does not substantially affect PPIs. We focused on methionine residues 144 and 145 in CaM because these amino acids were previously shown to play an important role in CyaA/CaM interaction [37]. Our molecular modeling studies predicted that the exchange of methionine against leucine at these positions would not exhibit a major impact on PPIs (Fig. 7). However, to our surprise, the "control" experiments with unoxidized CaM mutants revealed subtle differences between individual mutants that shed light onto the molecular mechanism of CyaA/CaM interactions.

Specifically, substitution of all nine methionines in CaM-215 resulted in an around threefold increase in the $\mathrm{EC}_{50}$ for $\mathrm{CaM}$ to activate catalysis and an approximately $15 \%$ decrease in the maximal catalytic activity of CyaA (Fig. 4 and Table 4). A loss of the first eight 
methionines (CaM-206 and CaM-213) increased the $\mathrm{EC}_{50}$ two-fold. However, methionine side chains are not essential for the CaM-dependent activation of CyaA as shown by the largely preserved function of CaM-215 which is devoid of methionine residues (Figs. 3 and 4). Methionine 145 slowed down $\mathrm{CaM} / \mathrm{CyaA}$ interaction substantially, whereas the impact of methionine 144 was moderate (Fig. 2 and Table 2). Thus, a leucine at position 145 facilitates the initial hydrophobic interactions between $\mathrm{CaM}$ and CyaA, probably because of the larger hydrophobic surface of leucine compared to methionine [30]. However, when the FRET signals under state-state conditions are considered, no differences in $\mathrm{EC}_{50}$ and efficacy between $\mathrm{CaM}$ and $\mathrm{CaM}$ mutants are apparent (Fig. 3 and Table 3). Nonetheless, when the endogenous tryptophan/tyrosine fluorescence signals of CyaA are considered it becomes evident that $\mathrm{CaM}$ mutants stabilize different CyaA conformations than CaM-WT (Fig. S1).

Mechanistically, dissociations in the effects of CaM-WT and CaM mutants between binding and catalysis indicate a two-step mechanism of CyaA activation. First, a complex between $\mathrm{CaM}$ and CyaA forms, followed by the activation of catalysis by $\mathrm{CaM}$. The binding of $\mathrm{CaM}$ to CyaA can be readily monitored in kinetic and steady-state fluorescence experiments, whereas the nature of the second conformational step leading to catalysis cannot be monitored individually with the methods currently available to us and is still elusive. The AC assay monitors the sum of steps 1 and 2. A two-step mechanism for activation of catalysis is also supported by the $\mathrm{CaM}$ inhibitor experiments in which we observed dissociations in the effects on FRET, direct fluorescence and catalysis (Fig. S5 and Fig. 5).

Two-step activation of catalysis has also been proposed for mammalian membranous ACs that are activated by the diterpene forskolin. Specifically, all diterpenes studied so far increase FRET from tyrosine and tryptophan residues in membranous AC to MANTnucleotides bound to the catalytic site, but only diterpenes substituted with a hydroxyl group at position 1 of the diterpene ring activate catalysis [27]. Thus, although CyaA and mammalian membranous ACs are structurally very different proteins as are the activation mechanisms $[1-4,20,38]$, fundamental regulatory principles are conserved in these proteins.

\subsection{Effects of CaM inhibitors on CyaA-CaM interaction}

Our data show that calmidazolium is the only one out of three classic CaM inhibitors studied (Fig. 1) capable of robustly inhibiting the catalytic activity of CyaA (Fig. 5). Previous studies revealed that these CaM inhibitors can exert their inhibitory effects by interacting with $\mathrm{CaM}$ or by modulating the $\mathrm{CaM}$ target structures [16-19,26,39]. In the case of CyaA, our results indicate that the inhibitory effect of calmidazolium is independent of CaM. This notion is supported by the finding that even in the absence of $\mathrm{CaM}$, calmidazolium inhibits catalysis (Fig. 5B). The biphasic inhibition isotherm indicates that calmidazolium possesses two functionally or structurally distinct binding sites on CyaA.

The affinity of CaM for calmidazolium is in the nM-range, whereas for trifluoperazine and W-7 affinities in the $\mu \mathrm{M}$-range are reported [26]. If one compares the structures of the three $\mathrm{CaM}$ inhibitors it becomes clear that calmidazolium possesses the most complex and bulky structure with its four aromatic rings (Fig. 1). It has been suggested that there is a correlation between the hydrophobicity and size of these compounds and their ability for $\mathrm{CaM}$ inhibition [18]. Thus, our data suggest that calmidazolium binds to one or two large hydrophobic pockets in CyaA and prevents conformational changes required for activation of catalysis. An interaction of calmidazolium with $\mathrm{CaM}$ does not appear to be important in this respect. A previous study showed that in intact $\mathrm{CHO}$ cells, calmidazolium inhibits CyaA-induced cAMP accumulation with an $\mathrm{IC}_{50}$ of $2.5 \mu \mathrm{M}$, but it remained unclear whether these effects were CaM-dependent or not [40]. 
Complex CaM-independent effects of calmidazolium were also reported for mammalian membranous ACs [41]. The structurally related nitric oxide-stimulated soluble guanylyl cyclase is inhibited by calmidazolium in a CaM-independent manner, too [42]. Moreover, apparently $\mathrm{CaM}$-independent effects of $\mathrm{CaM}$ antagonists on the superoxide-generating NADPH oxidase in intact human neutrophils were reported [43]. Thus, CaM antagonists in general and even the most potent $\mathrm{CaM}$ antagonist currently available, calmidazolium, are certainly not specific for CaM. The lack of selectivity of the currently available $\mathrm{CaM}$ antagonists for CaM severely limits their use for intact cell studies. In contrast, in studies with purified or recombinant proteins, selectivity of $\mathrm{CaM}$ antagonists, or lack thereof, can be readily assessed in control experiments without $\mathrm{CaM}$. Our present study highlights the importance for such control experiments.

\subsection{Interactions of $\mathrm{AC} 1$ with $\mathrm{CaM}$ : comparison with $\mathrm{CyaA}$}

An important goal in pharmacologically targeting the CyaA/CaM interaction is to leave the interaction of $\mathrm{CaM}$ with endogenous target proteins unaffected. While it is beyond the scope of this study to comprehensively examine selectivity of, or lack thereof, $\mathrm{CaM} / \mathrm{target}$ PPIs, we examined an important paradigmatic PPI, the $\mathrm{AC} 1 / \mathrm{CaM}$ interaction. $\mathrm{AC} 1$ is an important $\mathrm{AC}$ isoform exclusively expressed in neuronal cells that play a critical role in memory, learning, neuronal damage, and pain responses [20-23,38,44,45]. Thus, in case of whooping cough treatment, $\mathrm{AC} 1 / \mathrm{CaM}$ interaction should be left unaffected while in case of chronic pain and neuronal excitotoxicity, selective inhibition of the $\mathrm{AC} 1 / \mathrm{CaM}$ interaction may be desirable.

Although CaM activation of $\mathrm{AC} 1$ has been known for more than two decades [21], relatively little efforts have been undertaken so far to understand the molecular details of AC1/CaM interaction $[22,23,46]$ and accordingly, no targeted inhibitor studies have been performed. In marked contrast to the data obtained for CyaA, CaM mutants 214 and 215 were more effective than CaM-WT at activating catalysis. Moreover, the slope of CyaA activation by $\mathrm{CaM}$ was much steeper than the slope of $\mathrm{AC} 1$ activation (Figs. 4 and 6). Furthermore, the binding affinity of $\mathrm{CaM}$ for $\mathrm{CyaA}$ compared to $\mathrm{AC} 1$ was much higher. Lastly, CaM mutants showed decreases in potency relative to $\mathrm{CaM}$ with respect to CyaA activation but not with respect to $\mathrm{AC} 1$ activation. Collectively, these data demonstrate that the interactions of CyaA and $\mathrm{AC} 1$ with $\mathrm{CaM}$ are profoundly different.

Our data also suggest that the interaction of $\mathrm{AC} 1$ with $\mathrm{CaM}$ could be improved pharmacologically. CaM-215, devoid of all methionine residues, was the most effective $\mathrm{AC} 1$ activator. The higher efficacy of $\mathrm{CaM}$ mutants at $\mathrm{AC} 1$ compared to CaM-WT indicates that leucine substitutions facilitate hydrophobic $\mathrm{AC} 1 / \mathrm{CaM}$ interactions, thereby enhancing catalysis. These data also render it likely that oxidation of individual methionine residues will exhibit a larger impact on $\mathrm{AC} 1 / \mathrm{CaM}$ interactions than on $\mathrm{CyaA} / \mathrm{CaM}$ interactions. Thus, even these limited "control" experiments that were originally assumed to reveal no mechanistically relevant data, unmasked important differences in the interactions of CyaA and $\mathrm{AC} 1$ with $\mathrm{CaM}$. Based on these studies, the design of selective compounds targeting a defined $\mathrm{AC}$ isoform/CaM interaction is principally feasible.

\subsection{Concluding remarks and future directions of research}

Using CaM mutants and different functional assays, we obtained evidence for a two-step mechanism of CyaA activation which is conserved among ACs. The kinetics of CyaA/CaM interactions are sensitive to change in hydrophobicity, and classic CaM inhibitors do not effectively block CyaA/CaM interactions. Rather, the most potent CaM inhibitor known so far, calmidazolium, exhibits CaM-independent direct effects on the catalytic activity of CyaA. The lack of potent inhibition of $\mathrm{CyaA} / \mathrm{CaM}$ interaction by classic $\mathrm{CaM}$ inhibitors 
suggests that the PPI in this couple are different from the interactions of other effector/CaM interactions [24,32-35]. In principle, such differences offer the opportunity to develop inhibitors that specifically target the interaction between CyaA and $\mathrm{CaM}$ but not between endogenous proteins and $\mathrm{CaM}$, reducing potential side effects. Considering the fact that interactions of $\mathrm{CyaA}$ and $\mathrm{AC} 1$, an important mammalian target protein of $\mathrm{CaM}$, with $\mathrm{CaM}$ and $\mathrm{CaM}$ mutants are different, specific inhibition of $\mathrm{CyaA} / \mathrm{CaM}$ interactions is feasible.

Our present study also highlights the importance to carefully examine the properties of unoxidized CaM mutants since such proteins may differ more substantially from CaM-WT than is generally appreciated. Moreover, the detailed analysis of such mutants can be used to delineate the mechanisms of PPI interaction. Now that we have conducted a basic characterization of CaM mutants on CyaA and $\mathrm{AC} 1$, we are in the position to examine the impact of oxidation of individual methionine residues, using the properties of each unoxidized $\mathrm{CaM}$ mutant as control. In conjunction with molecular modeling studies, such studies will provide the basis for the development of specific small molecule PPI inhibitors. An advantage of targeting the $\mathrm{AC} / \mathrm{CaM}$ interaction site as compared to the catalytic site of $\mathrm{AC}$ is the fact that tentative inhibitors of $\mathrm{AC} / \mathrm{CaM}$ interactions will have to exhibit a moderate degree of lipophilicity, implying membrane-permeability and potential usefulness for intact cell studies. In contrast, while selective CyaA inhibitors targeting the catalytic site are already available [13,47], such compounds are not feasible for intact cell studies because of their lack of membrane-permeability. For the development of inhibitors of mammalian membranous ACs, we have come to the conclusion that targeting the allosteric "stimulatory" diterpene-binding site is more promising to achieve isoform-selective inhibitors than targeting the catalytic site [47]. By analogy, this may also apply to "stimulatory" $\mathrm{AC} / \mathrm{CaM}$ interaction sites.

\section{Supplementary Material}

Refer to Web version on PubMed Central for supplementary material.

\section{Acknowledgments}

The authors would like to thank Dr. Detlef Neumann for helpful discussions, Dr. Dietmar Manstein (Institute for Biophysical Chemistry, Medical School of Hannover) for granting us access to the Varian Cary Eclipse fluorescence spectrometer and the reviewers for their most helpful critique and suggestions. This work was supported by Deutsche Forschungsgemeinschaft grant Se 529/5-2 to R. S. and NIH grant GM62548 to W-.J. T.

\section{Abbreviations}

$\begin{array}{ll}\text { AC } & \text { adenylyl cyclase } \\ \text { AC1 } & \text { membranous adenylyl cyclase isoform 1 } \\ \text { CyaA } & \text { Bordetella pertussis adenylyl cyclase toxin } \\ \text { CaM } & \text { calmodulin } \\ \text { CaM-WT } & \text { wild-type calmodulin } \\ \text { FRET } & \text { fluorescence resonance energy transfer } \\ \text { 2'-MANT-3'-d-ATP }^{\prime} & \text { 2'-(N-methylanthraniloyl)-3'-deoxy-adenosine 5'-triphosphate } \\ \text { PPI } & \text { protein-protein interaction } \\ \text { W-7 } & \text { N-(6-aminohexyl)-5-chloro-1-naphthalenesulfonamide }\end{array}$




\section{References}

1. Vojtova J, Kamanova J, Sebo P. Bordetella adenylate cyclase toxin: a swift saboteur of host defense. Curr Opin Microbiol. 2006; 9:69-75. [PubMed: 16406775]

2. Ladant D, Ullmann A. Bordetella pertussis adenylate cyclase: a toxin with multiple talents. Trends Microbiol. 1999; 7:172-6. [PubMed: 10217833]

3. Shrivastava R, Miller JF. Virulence factor secretion and translocation by Bordetella species. Curr Opin Microbiol. 2009; 12:88-93. [PubMed: 19186097]

4. Tang WJ, Guo Q. The adenylyl cyclase activity of anthrax edema factor. Mol Aspects Med. 2009; 30:423-30. [PubMed: 19560485]

5. Marzouqui I, Richmond P, Fry S, Wetherall J, Mukkur T. Development of improved vaccines against whooping cough: current status. Hum Vaccin. 2010; 6:543-53. [PubMed: 20448470]

6. Grenfell B. Boosting understanding of pertussis outbreaks. Proc Natl Acad Sci U S A. 2011; 108:7279-80. [PubMed: 21508325]

7. Barret AS, Ryan A, Breslin A, Cullen L, Murray A, Grogan J, et al. Pertussis outbreak in northwest Ireland, January-June 2010. Euro Surveill. 2010; 15:19654. [PubMed: 20822735]

8. Berger F, Njamkepo E, Minaberry S, Mayet A, Haus-Cheymol R, Verret C, et al. Investigation on a pertussis outbreak in a military school: risk factors and approach to vaccine efficacy. Vaccine. 2010; 19:5147-52. [PubMed: 20541009]

9. Miyashita N, Kawai Y, Yamaguchi T, Ouchi K, Kurose K, Oka M. Outbreak of pertussis in a university laboratory. Intern Med. 2011; 50:879-85. [PubMed: 21498936]

10. Wall R, Bell A, Theobald J. Pertussis (whooping cough) epidemiology in Waikato, New Zealand: 2000-2009. N Z Med J. 2011; 124:52-61. [PubMed: 21747424]

11. Johnson RA, Shoshani I. Inhibition of Bordetella pertussis and Bacillus anthracis adenylyl cyclases by polyadenylate and P-site agonists. J Biol Chem. 1990; 265:19035-9. [PubMed: 2121733]

12. Göttle M, Dove S, Steindel P, Shen Y, Tang WJ, Geduhn J, et al. Molecular analysis of the interaction of Bordetella pertussis adenylyl cyclase with fluorescent nucleotides. Mol Pharmacol. 2007; 72:526-35. [PubMed: 17553924]

13. Geduhn J, Dove S, Shen Y, Tang WJ, König B, Seifert R. Bis-halogen-anthraniloyl-substituted nucleoside 5(-triphosphates as potent and selective inhibitors of Bordetella pertussis adenylyl cyclase toxin. J Pharmacol Exp Ther. 2011; 336:104-15. [PubMed: 20962032]

14. Laine E, Goncalves C, Karst JC, Lesnard A, Rault S, Tang WJ, et al. Use of allostery to identify inhibitors of calmodulin-induced activation of Bacillus anthracis edema factor. Proc Natl Acad Sci U S A. 2010; 107:11277-82. [PubMed: 20534570]

15. Lee YS, Bergson P, He WS, Mrksich M, Tang WJ. Discovery of a small molecule that inhibits the interaction of anthrax edema factor with its cellular activator, calmodulin. Chem Biol. 2004; 11:1139-46. [PubMed: 15324815]

16. Itoh $\mathrm{H}$, Hidaka $\mathrm{H}$. Direct interaction of calmodulin antagonists with $\mathrm{Ca}^{2+} /$ calmodulin-dependent nucleotide phosphodiesterase. J Biochem. 1984; 96:1721-6. [PubMed: 6099352]

17. Anderson KW, Coll RJ, Murphy AJ. Inhibition of skeletal muscle sarcoplasmic reticulum CaATPase activity by calmidazolium. J Biol Chem. 1984; 259:11487-90. [PubMed: 6236226]

18. Khan SZ, Longland CL, Michelangeli F. The effects of phenothiazines and other calmodulin antagonists on the sarcoplasmic and endoplasmic reticulum $\mathrm{Ca}^{2+}$ pumps. Biochem Pharmacol. 2000; 60:1797-806. [PubMed: 11108794]

19. Zimmer M, Hofmann F. Calmodulin antagonists inhibit activity of myosin light-chain kinase independent of calmodulin. Eur J Biochem. 1984; 142:393-7. [PubMed: 6547673]

20. Sadana R, Dessauer CW. Physiological roles for G protein-regulated adenylyl cyclase isoforms: insights from knockout and overexpression studies. Neuro-signals. 2008; 17:5-22. [PubMed: 18948702]

21. Tang WJ, Krupinski J, Gilman AG. Expression and characterization of calmodulin-activated (type I) adenylylcyclase. J Biol Chem. 1991; 266:8595-603. [PubMed: 2022671] 
22. Masada N, Ciruela A, Macdougall DA, Cooper DM. Distinct mechanisms of regulation by $\mathrm{Ca}^{2+} /$ calmodulin of type 1 and 8 adenylyl cyclases support their different physiological roles. J Biol Chem. 2009; 284:4451-63. [PubMed: 19029295]

23. Wang H, Storm DR. Calmodulin-regulated adenylyl cyclases: cross-talk and plasticity in the central nervous system. Mol Pharmacol. 2003; 63:463-8. [PubMed: 12606751]

24. Montgomery HJ, Bartlett R, Perdicakis B, Jervis E, Squier TC, Guillemette JG. Biochemistry (Activation of constitutive nitric oxide synthases by oxidized calmodulin mutants.). 2003; 42:7759-68. [PubMed: 12820885]

25. Sacksteder CA, Whittier JE, Xiong Y, Li J, Galeva NA, Jacoby ME, et al. Tertiary structural rearrangements upon oxidation of methionine 145 in calmodulin promotes targeted proteasomal degradation. Biophys J. 2006; 91:1480-93. [PubMed: 16751245]

26. Johnson JD, Wittenauer LA. A fluorescent calmodulin that reports binding of hydrophobic inhibitory ligands. Biochem J. 1983; 211:473-9. [PubMed: 6870843]

27. Pinto C, Hübner M, Gille A, Richter M, Mou TC, Sprang SR, et al. Differential interactions of the catalytic subunits of adenylyl cyclase with forskolin analogs. Biochem Pharmacol. 2009; 78:62-9. [PubMed: 19447224]

28. Erdorf M, Seifert R. Pharmacological characterization of adenylyl cyclase isoforms in rabbit kidney membranes. Naunyn-Schmiedeberg's Arch Pharmacol. 2011; 383:357-72. [PubMed: 21279330]

29. Shen Y, Lee YS, Soelaiman S, Bergson P, Lu D, Chen A, et al. Physiological calcium concentrations regulate calmodulin binding and catalysis of adenylyl cyclase exotoxins. EMBO J. 2002; 21:6721-32. [PubMed: 12485993]

30. Guo Q, Shen Y, Lee YS, Gibbs CS, Mrksich M, Tang WJ. Structural basis for the interaction of Bordetella pertussis adenylyl cyclase toxin with calmodulin. EMBO J. 2005; 24:3190-201. [PubMed: 16138079]

31. Pace CN, Scholtz JM. A helix propensity scale based on experimental studies of peptides and proteins. Biophys J. 1998; 75:422-7. [PubMed: 9649402]

32. O'Neil KT, DeGrado WF. How calmodulin binds its targets: sequence independent recognition of amphiphilic a-helices. Trends Biochem Sci. 1990; 15:59-64. [PubMed: 2186516]

33. Chin D, Means AR. Calmodulin: a prototypical calcium sensor. Trends Cell Biol. 2000; 10:322-8. [PubMed: 10884684]

34. Rhoads AR, Friedberg F. Sequence motifs for calmodulin recognition. FASEB J. 1997; 11:331-40. [PubMed: 9141499]

35. Hoeflich KP, Ikura M. Calmodulin in action: diversity in target recognition and activation mechnisms. Cell. 2002; 108:739-42. [PubMed: 11955428]

36. Guo Q, Jureller JE, Warren JT, Solomaha E, Florián J, Tang WJ. Protein-protein docking and analysis reveal that two homologous bacterial adenylyl cyclase toxins interact with calmodulin differently. J Biol Chem. 2008; 283:23836-45. [PubMed: 18583346]

37. Vougier S, Mary J, Dautin N, Vinh J, Friguet B, Ladant D. Essential role of methionine residues in calmodulin binding to Bordetella pertussis adenylate cyclase, as probed by selective oxidation and repair by the peptide methionine sulfoxide reductases. J Biol Chem. 2004; 279:30210-8. [PubMed: 15148319]

38. Sunahara RK, Taussig R. Isoforms of mammalian adenylyl cyclase: multiplicities of signaling. Mol Interventions. 2002; 2:168-84.

39. Asano M. Divergent pharmacological effects of three calmodulin antagonists, N-(6-aminohexyl)-5chloro-1-naphthalenesulfonamide (W-7), chlorpromazine and calmidazolium, on isometric tension development and myosin light chain phosphorylation in intact bovine tracheal smooth muscle. $\mathrm{J}$ Pharmacol Exp Ther. 1989; 251:764-73. [PubMed: 2810127]

40. Gentile F, Raptis A, Knipling LG, Wolff J. Bordetella pertussis adenylate cyclase. Penetration into host cells. Eur J Biochem. 1988; 175:447-53. [PubMed: 2900763]

41. Hauns $\varnothing$ A, Simpson J, Antoni FA. Small ligands modulating the activity of mammalian adenylyl cyclases: a novel mode of inhibition by calmidazolium. Mol Pharmacol. 2003; 63:624-31.

[PubMed: 12606770] 
42. James LR, Griffiths CH, Garthwaite J, Bellamy TC. Inhibition of nitric oxide-activated guanylyl cyclase by calmodulin antagonists. Br J Pharmacol. 2009; 158:454-64.

43. Seifert R, Schächtele C. Studies with protein kinase $C$ inhibitors presently available cannot elucidate the role of protein kinase $\mathrm{C}$ in the activation of NADPH oxidase. Biochem Biophys Res Commun. 1988; 152:585-92. [PubMed: 2835037]

44. Watts VJ. Adenylyl cyclase isoforms as novel therapeutic targets: an exciting example of excitotoxicity neuroprotection. Mol Interventions. 2007; 7:70-3.

45. Wang H, Xu H, Wu LJ, Kim SS, Chen T, Koga K, et al. Identification of an adenylyl cyclase inhibitor for treating neuropathic and inflammatory pain. Sci Transl Med. 2011; 3:65ra3.

46. Diel S, Beyermann M, Lloréns JM, Wittig B, Kleuss C. Two interaction sites on mammalian adenylyl cyclase type I and II: modulation by calmodulin and Gbg. Biochem J. 2008; 411:449-56. [PubMed: 18215138]

47. Seifert R, Lushington GH, Mou TC, Gille A, Sprang SR. Inhibitors of membranous adenylyl cyclases. Trends Pharmacol Sci. in press, doi:10.1016/j.tips.2011.10.006. 


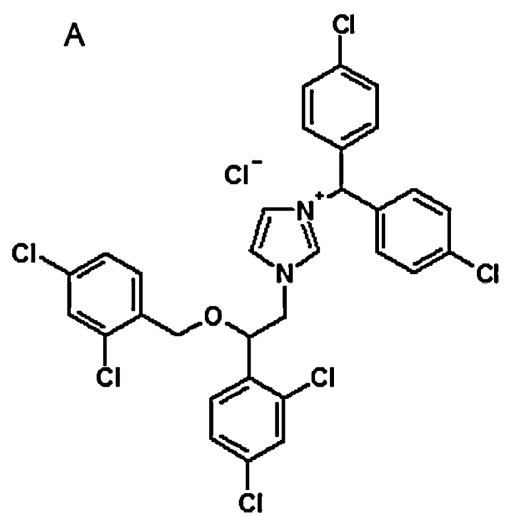

B<smiles>CN1CCN(CCCN2c3ccccc3Sc3ccc(C(F)(F)F)cc32)CC1</smiles>

C

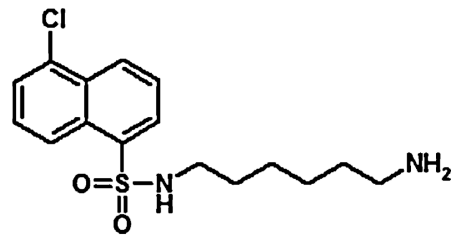

Fig. 1.

Structures of CaM antagonists. (A) Calmidazolium chloride; (B) trifluoperazine; and (C) W-7. 
A CaM-WT vs. CaM-206

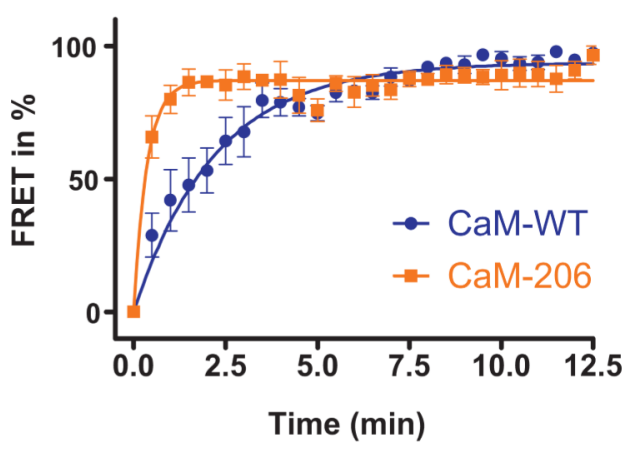

C CaM-WT vs. CaM-214

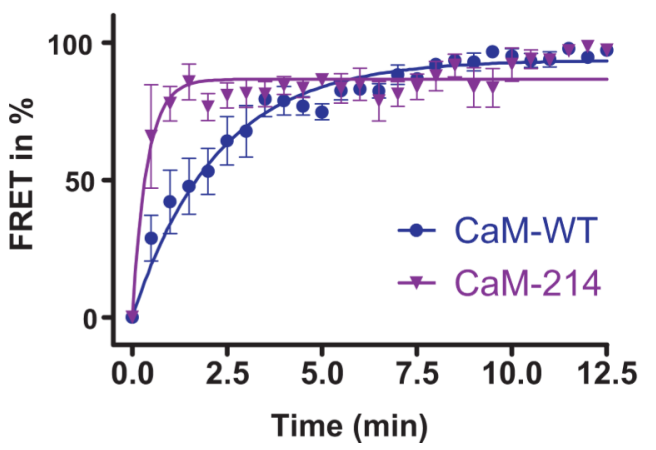

B CaM-WT vs. CaM-213

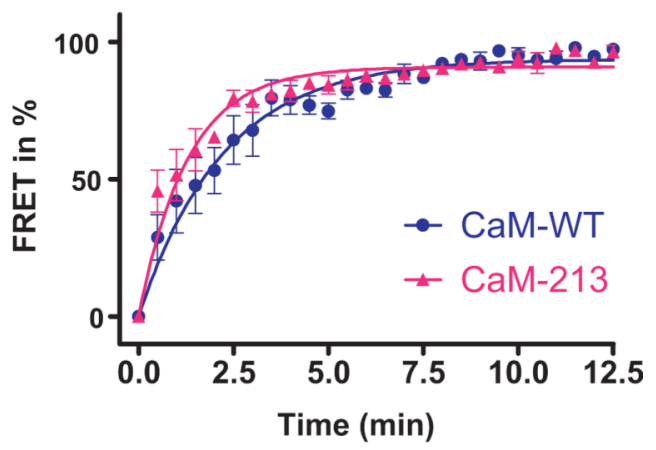

D CaM-WT vs. CaM-215

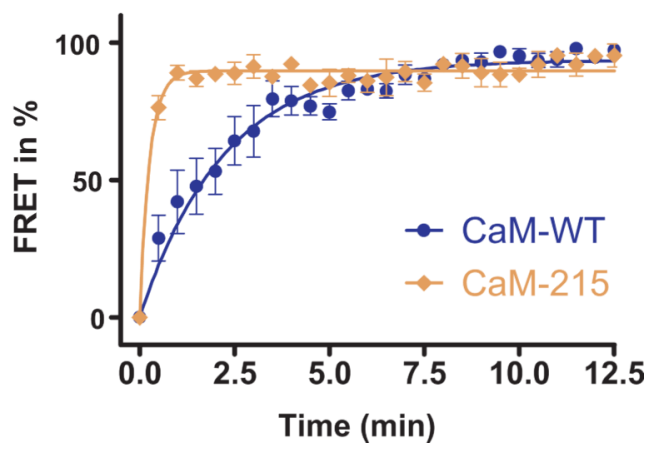

Fig. 2.

Kinetic analysis of the binding CaM-WT and CaM mutants to CyaA-N in FRET assays. Rate of binding CaM to CyaA-N over time was determined in FRET experiments as described in Section 2. The kinetic curves of binding $\mathrm{CaM}$ to CyaA-N were analyzed by the one-phase exponential association equation in Prism 5.04. Data shown are the means \pm SD of three independent expriments. 

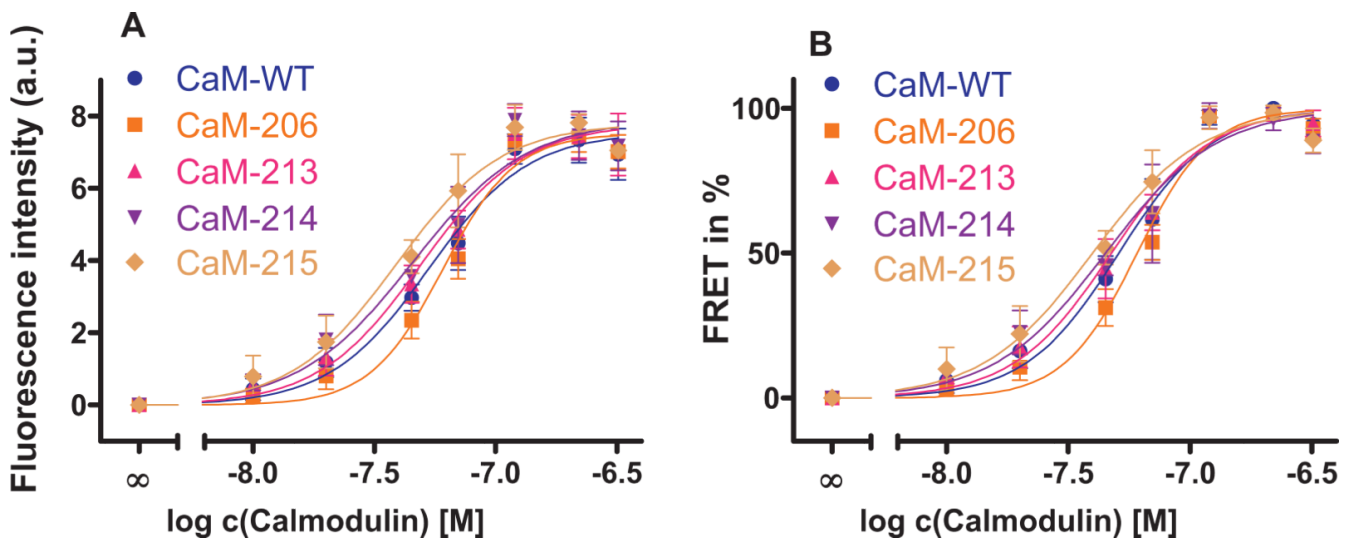

Fig. 3.

Concentration/response curves for the interaction of CyaA with $\mathrm{CaM}$ and $\mathrm{CaM}$ mutants in FRET assays. FRET was determined as described in Section 2. The cuvette contained 300 $\mathrm{nM}$ of $2^{\prime}$-MANT-3'-d-ATP and $300 \mathrm{nM}$ of CyaA-N. For assigning a FRET emission to each $\mathrm{CaM}$ concentration the arithmetic average of the last ten measuring points were used. The basal fluorescence (in this case reaction buffer + 2'-MANT-3'-dATP + CyaA-N) was subtracted from each data point. Concentration-response curves were analyzed by nonlinear regression using Prism 5.04 software. $r^{2}$ values were $>0.96$, except for that of CaM-214 which equaled 0.95 . The plots show the means \pm SD of three independent experiments. A shows the fluorescence intensity in arbitrary units, while in B the fluorescence was normalized, whereby $100 \%$ was defined as largest value in each data set. 

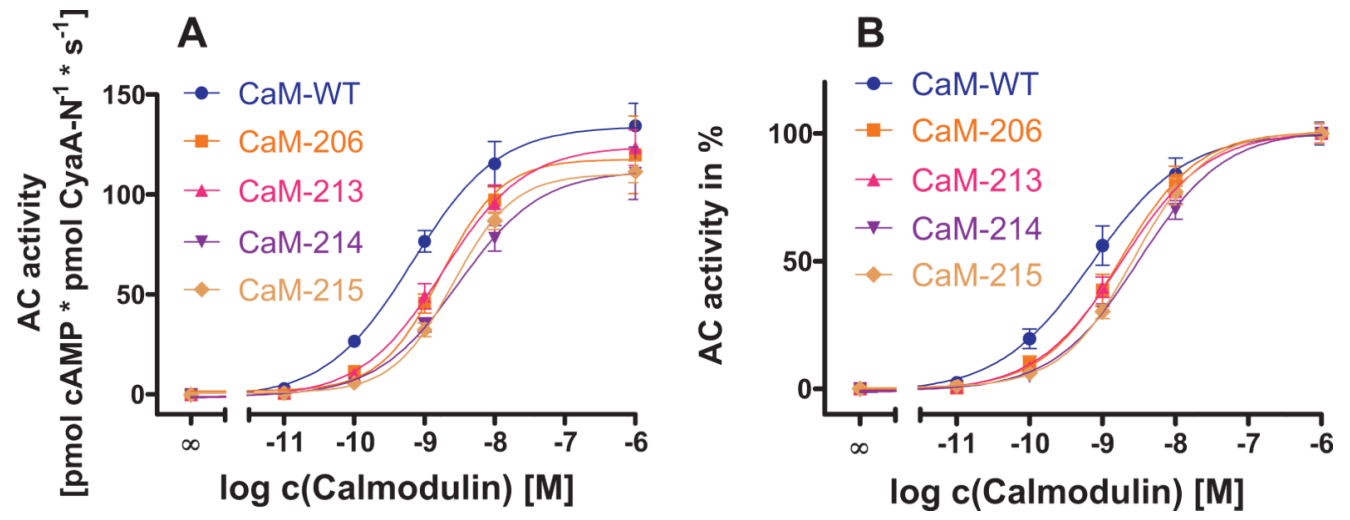

Fig. 4.

Concentration/response curves for the interaction of CyaA with CaM-WT and CaM mutants in AC assay. Reactions were carried out as described in Section 2. Final CyaA-N concentration was 10 pM and CaM-WT, CaM-206, CaM-213, CaM-214 or CaM-215 were added at concentrations from $10 \mathrm{pM}$ to $1 \mu \mathrm{M}$. Reactions were started by the addition of the toxin. Concentration-response curves were analyzed by nonlinear regression using Prism 5.04. $r^{2}$ values were $>0.97$. Data show the means \pm SD of three independent experiments. A shows the AC activity in pmoles of cAMP formed per pmol CyaA-N per second, while in B the AC activity was normalized, whereby $100 \%$ was defined as largest value in each data set. 

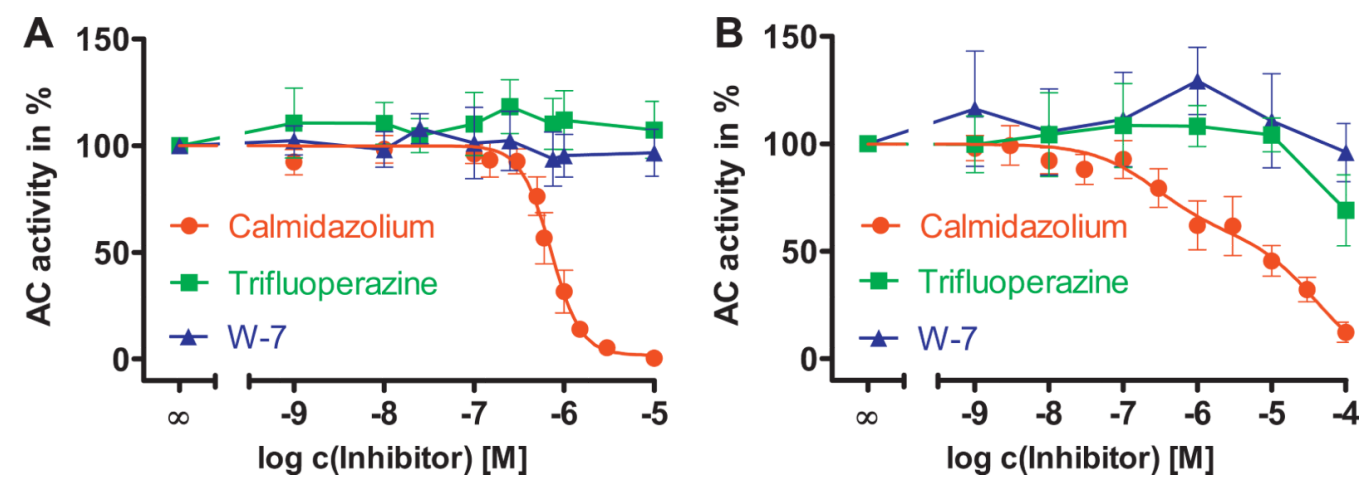

Fig. 5.

Effects of CaM inhibitors on the AC activity of CyaA in the presence and the absence of CaM-WT. (A) AC activity in the presence of CaM. Assays were performed as described in Section 2. Reaction mixtures contained $1 \mathrm{nM}$ CaM-WT, $10 \mathrm{pM}$ CyaA-N and CaM inhibitors (calmidazolium, trifluoperazine or $\mathrm{W}-7)$ in various concentrations $(1 \mathrm{nM}$ to $10 \mu \mathrm{M})$. The calmidazolium inhibition curve was analyzed by nonlinear regression using Prism 5.04. Data show the means \pm SD of three independent experiments. Assays were performed as duplicate or triplicate. AC activity was normalized with respect to the initial activity in the absence of inhibitor. (B) AC activity in the absence of CaM. Assays were performed as described in Section 2. Reaction mixtures contained $100 \mathrm{pM} \mathrm{CyaA}$, and concentrations of CaM-inhibitors (calmidazolium, trifluoperazine or $\mathrm{W}-7$ ) ranged from $1 \mathrm{nM}$ to $100 \mu \mathrm{M}$. The calmidazolium inhibition curve was analyzed by nonlinear regression using Prism 5.04. Data show the means \pm SD of three independent experiments. Assays were performed as duplicate or triplicate. AC activity was normalized with respect to the initial activity in the absence of inhibitor. 


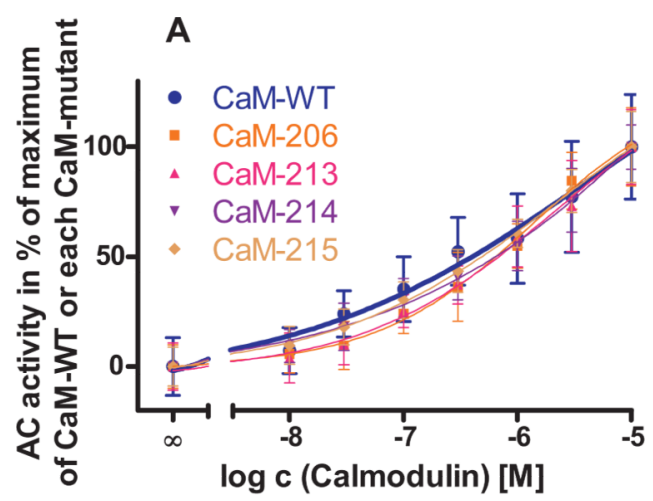

B

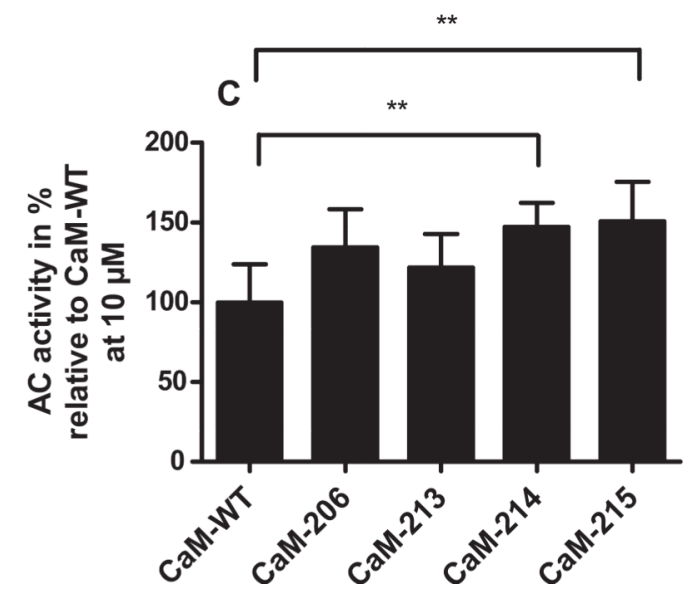

Fig. 6.

Concentration/response curves for the interaction of $\mathrm{AC} 1$ with CaM-WT and CaM mutants in AC assay. Reactions were carried out as described in Section 2. The concentrations of $\mathrm{CaM}$ and $\mathrm{CaM}$ mutants were varied between $10 \mathrm{nM}-10 \mu \mathrm{M}$. Concentration-response curves were analyzed by nonlinear regression using Prism 5.04. Specifically, data were compared for best fit to sigmoidal concentration/response curves or variable slope concentration/ response curves, the latter providing a better fit in all cases. (A) comparison of the potencies of CaM-WT and CaM mutants with the maximum effect of each $\mathrm{CaM}$ protein at $10 \mu \mathrm{M}$ being set to $100 \%$. B, comparison of the effects of CaM-WT and CaM mutants with the maximum effect of CaM-WT being set to $100 \%$. C, comparison of the effects of CaM mutants at a concentration of $10 \mu \mathrm{M}$ each relative to CaM-WT. ${ }^{* *} p<0.01$. Data show the means \pm SD of three independent experiments performed in duplicates. 


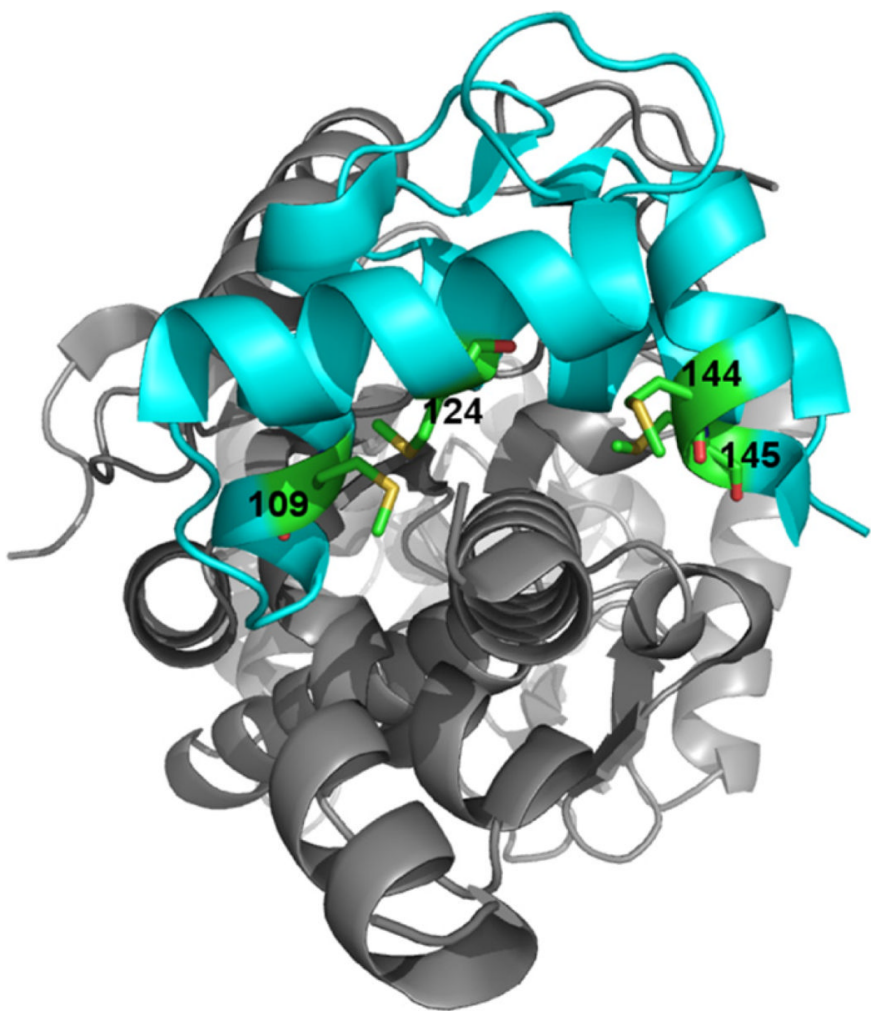

Fig. 7.

Molecular modeling of the interaction of CyaA with CaM. Interaction complex of CyaA (grey ribbons) and CaM (cyan ribbons) showing the location of four crystallographically resolved methionine residues (CPK-colored sticks with green carbon atoms) that have been subjected to leucine mutational analysis. The basis of the model is the crystal structure PDB 1YRT. (For interpretation of the references to color in this figure legend, the reader is referred to the web version of the article.) 


\section{Table 1}

Nomenclature of analyzed CaM mutants.

\begin{tabular}{lll}
\hline CaM & Methionines & Leucine substitutions \\
\hline Wild-type & $36,51,71,72,76,109,124,144,145$ & None \\
206 & 144,145 & $36,51,71,72,76,109,124$ \\
213 & 145 & $36,51,71,72,76,109,124,144$ \\
214 & 144 & $36,51,71,72,76,109,124,145$ \\
215 & None & $36,51,71,72,76,109,124,144,145$ \\
\hline
\end{tabular}

Positions of methionines and their associated site-directed leucine substitutions for wild-type CaM and indicated CaM mutants. 
Table 2

Analysis of the binding kinetics of CaM-WT and CaM mutants to CyaA.

\begin{tabular}{lll}
\hline Calmodulin & $\boldsymbol{K}\left(\mathbf{m i n}^{-1}\right)$ & Half-life $(\mathbf{m i n})$ \\
\hline CaM-WT & $0.568 \pm 0.24$ & $1.625 \pm 0.48$ \\
CaM-206 & $2.977 \pm 0.67$ & $0.254 \pm 0.05^{* *}$ \\
CaM-213 & $0.873 \pm 0.23$ & $0.902 \pm 0.21$ \\
CaM-214 & $3.902 \pm 1.33^{*}$ & $0.248 \pm 0.11^{* *}$ \\
CaM-215 & $3.978 \pm 0.51^{*}$ & $0.180 \pm 0.02^{* *}$ \\
\hline
\end{tabular}

Listed are the means and standard errors of three independent experiments. The basis for the analysis are the experiments shown in Fig. 2. $K$ is the association rate constant expressed in $\min ^{-1}$, and half-life expressed in $\min$ is the time required for CaM to bind $50 \%$ of the available CyaA-N molecules. A one-way analysis of variance with a Dunnett's multiple comparison post test with CaM-WT as control were performed to find out significant differences in $\mathrm{K}$ and half-life values of the calmodulin mutants with reference to CaM-WT.

No *: $p$-value $>0.05$.

*0.01<p-value $<0.05$.

**

$0.001<p$-value $<0.01$ 


\section{Table 3}

Analysis of the concentration/response curves for the interaction of CyaA with CaM-WT and CaM mutants in FRET assays.

\begin{tabular}{llr}
\hline Calmodulin & \multicolumn{2}{c}{ Fluorescence resonance energy transfer } \\
\cline { 2 - 3 } & $\mathbf{E C}_{\mathbf{5 0}}(\mathbf{n M})$ & $\boldsymbol{E}_{\mathbf{m a x}}(\boldsymbol{\%})$ \\
\hline CaM-WT & $52 \pm 9$ & 100 \\
$\mathrm{CaM}-206$ & $60 \pm 6$ & $101 \pm 7$ \\
$\mathrm{CaM}-213$ & $48 \pm 9$ & $103 \pm 18$ \\
$\mathrm{CaM}-214$ & $46 \pm 3$ & $101 \pm 1$ \\
$\mathrm{CaM}-215$ & $40 \pm 8$ & $104 \pm 11$ \\
\hline
\end{tabular}

The experiments shown in Fig. 3 are the basis for the analysis. Concentration-response curves were analyzed by nonlinear regression using Prism 5.04. EC50 and $E_{\max }$ represent the means \pm SD of three independent experiments. A one-way analysis of variance with a Dunnett's multiple comparison post test with CaM-WT as control were done to find out significant differences in $\mathrm{EC}_{50}$ and $E_{\max }$ values of the calmodulin mutants with reference to CaM-WT. 


\section{Table 4}

Analysis of the concentration/response curves for the interaction of CyaA with CaM-WT and CaM mutants in the AC assay.

\begin{tabular}{llc}
\hline Calmodulin & \multicolumn{1}{c}{ AC activity } & \\
\cline { 2 - 3 } & $\mathbf{E C}_{\mathbf{5 0}}(\mathbf{n M})$ & $\boldsymbol{E}_{\mathbf{m a x}}(\boldsymbol{\%})$ \\
\hline $\mathrm{CaM}-\mathrm{WT}$ & $0.8 \pm 0.3$ & 100 \\
$\mathrm{CaM}-206$ & $1.8 \pm 0.7^{*}$ & $90 \pm 4$ \\
$\mathrm{CaM}-213$ & $1.8 \pm 0.2^{*}$ & $93 \pm 2$ \\
$\mathrm{CaM}-214$ & $3.2 \pm 0.4^{* * *}$ & $85 \pm 8^{*}$ \\
$\mathrm{CaM}-215$ & $2.7 \pm 0.1^{* * *}$ & $84 \pm 5^{* *}$ \\
\hline
\end{tabular}

The experiments shown in Fig. 4 are the basis for the analysis. Concentration-response curves were analyzed by nonlinear regression using Prism 5.04. EC50 and $E_{\max }$ represent the means \pm SD of three independent experiments. A one-way analysis of variance with a Dunnett's multiple comparison post test with CaM-WT as control were computed to find out significant differences in $\mathrm{EC}_{50}$ and $E_{\max }$ values of the calmodulin mutants with reference to CaM-WT.

No*: $p$-value $>0.05$.

* $0.01<p$-value $<0.05$.

**

$0.001<p$-value $<0.01$.

$* * *$

$p$-value $<0.001$ 